\title{
The influence of abstract and concrete mindsets on anticipating and guiding others' self-regulatory efforts ${ }^{\text {is }}$
}

\author{
Antonio L. Freitas, ${ }^{\mathrm{a}, *}$ Peter Gollwitzer, ${ }^{\mathrm{b}}$ and Yaacov Trope ${ }^{\mathrm{b}}$ \\ ${ }^{a}$ Department of Psychology, State University of New York, Stony Brook, NY 11794-2500, USA \\ ${ }^{\mathrm{b}}$ Department of Psychology, New York University, USA
}

\begin{abstract}
To investigate how people anticipate and attempt to shape others' self-regulatory efforts, this work examined the impact of abstract and concrete mindsets on attention to goal-relevant aspects of others' situations. An abstract (relative to a concrete) mindset, by making accessible the cognitive operation of considering activities' purpose (versus process) was predicted to focus attention on how others' self-evaluative situations could impact others' long-term aims of self-knowledge and self-improvement, thus facilitating the anticipation and preference that others pursue accurate, even self-critical, feedback. Participants in an abstract (relative to a concrete) mindset both anticipated (Experiment 1) and suggested (Experiments 2a and b) that others pursue realistic rather than overly positive self-relevant information, with the latter effect apparently explained by the salience of abstract versus concrete goal-relevant features of others' situations (Experiment 2b). Implications for self-regulatory mindsets, as well as for interpersonal relations, are discussed.
\end{abstract}

\section{Introduction}

Knowing a person's goals facilitates understanding and predicting the person's behaviors. Accordingly, not only researchers of personality (e.g., Adler, 1927; Cantor, 1994; Emmons, 1989; Grant \& Dweck, 1999; Mischel, 1973) but also ordinary observers seek the goals underlying others' behaviors and rely on goal-related assumptions to predict others' future behaviors (e.g., Bassili, 1989; Read \& Miller, 1993). Moreover, as work supervisors, teachers, siblings, caring friends, and parents can attest, people often must guide others toward appropriate goals in given situations. How do people meet the related challenges of anticipating and guiding others' self-regulatory efforts?

\footnotetext{
We thank Ana Díaz, Michelle Gomez, Jessica Velasquez, and Rosemary Ventura for invaluable assistance in the coding of free responses. Parts of this work were completed while pre-doctoral fellowships from the Ford Foundation and the Jacob K. Javits program supported the first author.

${ }^{*}$ Corresponding author.

E-mail address: antonio.freitas@sunysb.edu (A.L. Freitas).
}

Answering both questions appears to depend substantially on how people view others' situations. Situational inducements, potential rewards versus penalties for performing particular acts, help people identify the goals and aims likely underlying others' behaviors (Chun, Spiegel, \& Kruglanski, 2002; Trope, 1986; Trope \& Alfieri, 1997). ${ }^{1}$ Even without observing others' behaviors, moreover, people use situational cues to determine the goals others' situations afford attaining (Gibson, 1979/1986; Proffitt, Stefanucci, Banton, \& Epstein, 2003; Rochat, 1995; Stroffregen, Gorday, Sheng, \& Flynn, 1999). Thus, people expect others to pursue different goals in different situations, such as job interviews, fraternity parties, and first dates (Cantor, Mischel, \& Schwartz, 1982). In much the same vein, people guide others toward goals sensitive to situational

\footnotetext{
${ }^{1}$ How such identifications of actors' aims in a situation influence inferences of the actor's underlying, stable dispositions, an issue central to much person-perception research (e.g., Gilbert, 1998; Trope \& Gaunt, 1999), lies beyond the immediate scope of this investigation, although we touch briefly upon the issue in the General discussion, under the heading, "Interpersonal implications."
} 
constraints (for reviews, see Andersen \& Chen, 2002; Moretti \& Higgins, 1999b). Parents' influences on their children's academic performance, for example, are contextualized, with some inspiring stronger efforts in creative situations and others inspiring stronger efforts in analytic situations (Shah, 2003). Situational cues thus appear central to anticipating and guiding others' selfregulatory efforts.

Any situation, however, likely contains multiple goal-relevant cues, each of which can be construed in myriad ways (cf. Brown, 1958). What determines the impact of one's particular construal of another's situation on one's inferences concerning the other's selfregulatory efforts? Arguably the most fundamental task of self-regulation is balancing abstract, long-term aims with immediate, concrete experiences, as when a child delays enjoying a cookie to receive two later, a smoker eschews a cigarette in the service of better health, or a student endures a rigorous study session on the road to a better grade (e.g., Mischel, Shoda, \& Rodriguez, 1989; Rachlin, 2000; Trope \& Fishbach, 2000). Accordingly, construing others' situations in terms of the abstract aims versus immediate experiences they afford attaining, by highlighting quite distinct situational inducements, should influence particularly potently one's anticipation and guidance of others' self-regulatory efforts. Focusing on the lowlevel, concrete experiences afforded by another's situation should lead one to both expect and prefer that the other pursue the most comfortable and feasible means of action, given that rewards and punishments associated with the process of the activity would be most salient. Focusing on the high-level, abstract aims afforded by another's situation, in contrast, should lead one to both expect and prefer that the other pursue the action providing the greatest long-term benefits, given that rewards and punishments associated with the ultimate aim of the activity would be most salient (cf., Liberman \& Trope, 1998; Vallacher \& Kaufman, 1996). Previously unexplored determinants of such construals, we suggest, are abstract and concrete mindsets.

\section{Abstract and concrete mindsets}

Any action can be construed at varying levels of abstraction, from low levels, specifying how it is performed, to high levels, specifying why it is performed (Vallacher \& Wegner, 1985, 1987). High-level, why, construals represent the action's purpose and thus are of primary concern when contemplating an action. Low-level, how, construals represent the action's process and thus are of secondary concern when contemplating an action (Trope \& Liberman, 2003). Locking a door, for example, could be construed as "turning a key," a relatively low-level identification of the process of how one locks a door, or as "securing one's home," a relatively high-level identification of the purpose of why one locks a door (Vallacher \& Wegner, 1989). Focusing directly on a situation's low-level or high-level contents, as when an interaction partner focuses on (low-level) speech utterances or (high-level) interaction aims, directly influences one's construal of the situation (e.g., Vallacher, Wegner, McMahan, Cotter, \& Larsen, 1992).

Independent of information specific to a particular situation, however, the accessibility of cognitive operations can influence more generally how new information is processed in new situations. As first demonstrated early last century, encountering tasks requiring the use of a particular cognitive operation, such as inverting letters in a particular way to solve anagrams, increases the operation's likelihood of usage on upcoming tasks (e.g., Ach, 1910; Külpe, 1904; Rees \& Israel, 1935). Examining the role that these differing accessibilities of cognitive operations, contemporarily termed mindsets, play in self-regulation, recent work has exploited Heckhausen's (1986) parsing of self-regulation into four distinct phases: (a) deliberating whether to take action, (b) planning action implementation, (c) taking action, and (d) evaluating action. Focusing on the first two, preactional phases, this work posits that each phase requires its own distinct cognitive operations, which, once accessible due to recent usage, color how people interpret newly encountered information (Gollwitzer, 1990; Gollwitzer \& Bayer, 1999). In one study, for instance, participants either were held in a pre-decisional, deliberative state or were pushed to make a decision and to plan implementation (Gollwitzer, Heckhausen, \& Ratajczak, 1990). On a test of their memory concerning a subsequent, unrelated task, participants in the deliberative condition recalled greater amounts of deliberative information, whereas participants in the implementational condition recalled greater amounts of implementation-related information. Such findings show that making accessible distinct cognitive operations can orient one towards congruent information, across different content domains.

These considerations imply that thinking about the abstract aims (versus concrete procedures) related to one activity or situation could increase the accessibility of the general cognitive operation of considering activities' purpose (versus process), thus coloring one's construal of a newly encountered activity or situation. Given the assumption that balancing long-term, abstract aims and immediate, concrete experiences constitutes the core essence of self-regulation (e.g., Mischel et al., 1989; Rachlin, 2000; Trope \& Fishbach, 2000), this hypothesized applicability of an abstract or concrete mindset across different content domains holds particular relevance for anticipating and guiding the self-regulatory efforts of others, who, because they are 
others (and not oneself) likely face situations nonidentical to one's own. Might considering why rather than how to improve one's own health, for example, influence whether one construes another person's nonhealth-related situation in terms of its impact on abstract, long-term aims rather than on immediate, concrete experiences?

Pursuing these questions requires an approach different from earlier work on deliberative and implementational mindsets (Gollwitzer, 1990; Gollwitzer \& Bayer, 1999). Consistent with the current aims, adopting a deliberative mindset, that is, considering potential pros versus cons of particular courses of action, should highlight the abstract, high-level value of activities, and adopting an implementational mindset, that is, planning how to carry out activities, should highlight the concrete, low-level procedures that comprise activities. However, reflecting the conceptual attribution of deliberative and implementational mindsets to naturally occurring action phases (Heckhausen \& Gollwitzer, 1987), a deliberative mindset additionally entails being undecided about an issue, and an implementational mindset additionally entails being decided about an issue (Gollwitzer, 1990). Independent of any effects of abstract versus concrete construals reflecting the accessibility of cognitive operations, then, decisional status alone could impact motivation-related variables. Once decided upon an issue, that is, people favor information supporting their decision over information challenging it (e.g., Brehm \& Cohen, 1962; Kunda, 1990; Zakay \& Tsal, 1993). Importantly, moreover, such motivational effects can carry over to newly encountered situations. Accordingly, Taylor and Gollwitzer (1995) showed that participants in an implementational mindset (who had planned the implementation of a previously decidedupon course of action) viewed objective risk factors more favorably (i.e., as less likely to impact them) than did participants in a deliberative mindset (who had deliberated whether or not to undertake a previously undecided course of action). Gollwitzer and Kinney (1989) suggest that such effects indicate that implementational mindset manipulations generate broad determination to complete whatever task may be at hand, thus fostering the illusion that situational affordances are overly supportive of whatever goals one may hold. Further supporting a motivational interpretation, implementational mindset manipulations increase cognitive dissonance effects, fostering greater devaluation of non-chosen alternatives and greater valuation of chosen alternatives (Harmon-Jones \& Harmon-Jones, 2002). Extant mindsets effects, then, appear to depend not only cognitive operations made accessible through thinking abstractly versus concretely but also on motivation generated through commitment to decisions.

\section{Current research}

In the experiments described herein, we instilled general abstract and concrete mindsets independently of participants' decisional statuses. We next assessed participants' anticipations (Experiments 1 and 2) and preferred guidance (Experiment 2) of others' self-regulatory efforts. The self-regulatory domain upon which we focused was self-evaluation. The process of evaluating oneself can be considered a self-regulatory tradeoff between seeking immediate, concrete benefits, through acquiring positive, pleasant-to-receive feedback, and seeking longer-term, more abstract benefits, through acquiring accurate feedback that may be unpleasant to receive but quite useful for attempts at self-improvement (Freitas, Salovey, \& Liberman, 2001; Mischel, Ebbesen, \& Zeiss, 1973; Trope \& Neter, 1994). We tested whether one's general mindset could influence the relative salience of these concrete versus abstract situational inducements present in others' situations. If an abstract mindset highlights the high-level, abstract aims afforded by another's self-evaluative situation, then undergoing an abstract mindset manipulation should lead one to both expect and suggest that the other pursue accurate, realistic information, because such information would provide the greatest abstract, long-term benefits. If a concrete mindset, in contrast, highlights the low-level, concrete experiences afforded by another's situation, then undergoing a concrete mindset manipulation should lead one to both expect and suggest that the other pursue positive feedback, because such information would provide the greatest immediate, concrete benefits.

\section{Experiment 1}

Participants assigned to an abstract mindset condition were directed to consider why they would engage in an activity (health improvement), whereas participants assigned to a concrete mindset condition were directed to consider how they would engage in the same activity. As illustrated in Fig. 1, structuring these thought exercises were diagrams requiring participants to think either: (a) increasingly abstractly about the activity, by successively indicating why they would engage in it as well as the higher-level goals served by it or (b) increasingly concretely about the activity, by successively indicating how they would engage in it as well as the lower-level activities comprising it. Accordingly, by focusing all participants on the same activity, this manipulation holds constant decisional status, as well as content domain, while varying only abstraction level.

We tested the impact of this mindset manipulation on participants' inferences regarding others' efforts in 


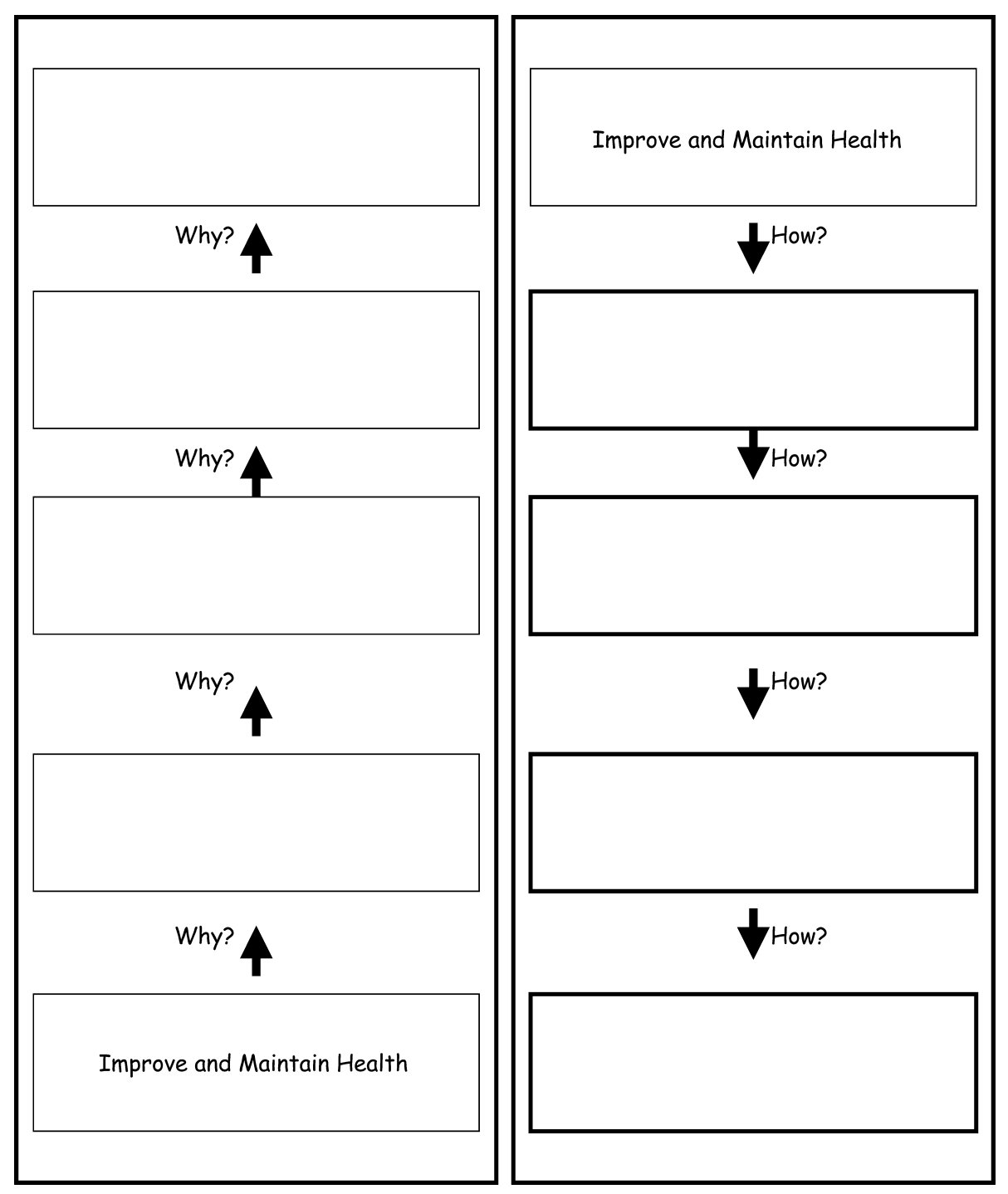

Fig. 1. Diagram directing participants to think increasingly abstractly (left panel) or increasingly concretely (right panel) about action, which served as a component of general abstract versus concrete mindset inductions (see text for fuller explanation).

a different self-regulatory domain, self-evaluation. Selfrelevant information can focus on personal strengths or weaknesses. Whereas both types of feedback can help people plan appropriate effort expenditure, weaknesses-based feedback, although less pleasant to receive, can help people identify skills they need to improve (e.g., Dweck, 1998; Dweck \& Leggett, 1988; Freitas et al., 2001; Trope \& Neter, 1994; see also Carver \& Scheier, 1999). If an abstract mindset focuses one's attention on how others' self-evaluative situations can help realize the abstract objectives of self-knowledge and self-improvement, whereas a concrete mindset focuses one's attention on how others' self-evaluative situations can impact immediate comfort during the self-evaluative process itself, then participants in an abstract (rather than concrete) mindset should be more likely: (a) to expect others to be willing to receive weaknesses-focused (rather than strengths-focused) feedback and (b) to endorse others' receipt of weaknesses-focused (rather than strengthsfocused) feedback.

\section{Method}

\section{Participants}

One hundred twenty undergraduates participated in exchange for credit toward an introductory psychology course.

\section{Procedure}

Based on random assignment, participants completed either the abstract or concrete versions of the mindset manipulation described below. All participants next learned of and answered questions about a high school social-intelligence assessment, described below. 


\section{Mindset induction ${ }^{2}$}

Participants were assigned randomly to plan how they could implement an activity or to consider why they would engage in the activity. Participants in the abstract condition considered why they would improve and maintain their health. As an introduction to this exercise, these participants read a passage describing why a person might want to complete a mundane action, participating in a psychology experiment. This passage appears below.

\begin{abstract}
For every thing we do, there always is a reason why we do it. Moreover, we often can trace the causes of our behavior back to broad life-goals that we have. For example, you currently are participating in a psychology experiment. Why are you doing this? Perhaps to satisfy a course requirement. Why are you satisfying the course requirement? Perhaps to pass a psychology course. Why pass the course? Perhaps because you want to earn a college degree. Why earn a college degree? Maybe because you want to find a good job, or because you want to educate yourself. And perhaps you wish to educate yourself or find a good job because you feel that doing so can bring you happiness in life. Research suggests that engaging in thought exercises like that above, in which one thinks about how one's actions relate to one's ultimate life goals, can improve people's life satisfaction. In this experiment, we are testing such a technique. This thought exercise is intended to focus your attention on why you do the things you do. For this thought exercise, please consider the following activity: 'improving and maintaining one's physical health.'
\end{abstract}

After reading the passage, participants assigned to the abstract condition listed three ways in which improving and maintaining their physical health could help them meet important life goals. In reference to each goal they listed, participants used a 5-point scale $(1=$ a little; $5=$ very, very much) to answer the question, "How much will improving and maintaining your health help you meet this important goal?"' Participants in the abstract condition lastly completed a diagram (see Fig. 1,

\footnotetext{
${ }^{2}$ In a pilot study with 66 participants, we examined the impact of this manipulation on linguistic indicators of abstract versus concrete thinking. Based on the linguistic category model (Semin \& Fiedler, 1988, 1992), we gauged the abstraction level of participants' responses according to the types of verbs and adjectives used to complete the empty boxes in the mindset induction. Using Semin and Smith's (1999; cf. Semin \& Fiedler, 1988) coding scheme, we assigned scores of 1, 2, 3, and 4 to descriptive action verbs, interpretive action verbs, state verbs, and adjectives, respectively. Two independent coders unaware of our hypotheses made these ratings with a high degree of reliability $(95 \%$ agreement). The resulting score reflects degree of abstraction, with higher scores indicating greater abstraction levels (i.e., greater independence of contextual detail). These scores were then divided by the total number of words generated during the mindset task, providing each participant with a single score indicating average level of abstraction across all generated words. As expected, participants who received the abstract mindset induction used language reflecting a higher abstraction level $(M=.82)$ than did participants who received the concrete mindset induction $(M=.41, t(64)=5.90, p<.0001$, Cohen's $d=1.47$ ). This finding strongly suggests that the different mindset inductions successfully led participants to represent action differentially abstractly.
}

left panel) showing how improving and maintaining their health could help them meet their important life goals.

Participants assigned to the concrete mindset condition read a passage containing factual information identical to that provided in the abstract condition. Whereas the "abstract" passage focused participants' attention on why they might participate in a psychology experiment (to find happiness in life), however, the "concrete" passage focused participants' attention on how they might find happiness in life (by participating in a psychology experiment):

\footnotetext{
For everything we do, there always is a process of how we do it. Moreover, we often can follow our broad life-goals down to our very specific behaviors. For example, like most people, you probably hope to find happiness in life. How can you do this? Perhaps finding a good job, or being educated, can help. How can you do these things? Perhaps by earning a college degree. How do you earn a college degree? By satisfying course requirements. How do you satisfy course requirements? In some cases, such as today, you participate in a psychology experiment. Research suggests that engaging in thought exercise like that above, in which one thinks about how one's ultimate life goals can be expressed through specific actions, can improve people's life satisfaction. In this experiment, we are testing such a technique. This thought exercise is intended to focus your attention on how you do the things you do. For this thought exercise, please consider the following activity: 'improving and maintaining one's physical health.'
}

After reading the passage, participants assigned to the concrete condition listed three means by which they could improve and maintain their health. In reference to each means they listed, participants used a 5-point scale $(1=$ a little; $5=$ very, very much $)$ to answer the question, "How much will engaging in this activity improve and maintain your health?" Participants in the concrete condition lastly completed a diagram (see Fig. 1, right panel) showing how they could improve and maintain their health.

Accordingly, participants assigned to both the concrete and the abstract conditions considered the same activity, health improvement, although participants in the concrete condition considered how they could improve their health and participants in the abstract condition considered why they would improve their health.

\section{Others' social intelligence}

In an ostensibly unrelated task, all participants next learned of a social-intelligence assessment program (adapted from Freitas et al., 2001; Study 3) that we purportedly were developing for use with high school students:

Social intelligence refers to people's ability to get along well with others. People who are highly socially intelligent usually know the right things to say and do in social, professional, and educational settings. In contrast, people with low social intelligence tend to insult or offend other people (often without even knowing it), so they have a hard time cultivating truly 
meaningful relationships with other people or performing up to their full potential at work and at school. Our research group, in collaboration with several others, is developing an assessment of social intelligence among high school students. In deciding how to provide feedback to these students, we are seeking the advice of people of various age groups. In this questionnaire, we are interested in your opinion about providing social intelligence feedback to high school students.

The issue of providing positive versus negative feedback we described as follows:

Our assessment of social intelligence includes two components: The "Weaknesses Component" is designed to point out areas where high school students' social intelligence is low and in need of improvement. The results can help pinpoint their weaknesses and show how they could be damaging their lives. The "Strengths Component" is designed to point out areas where high school students' social intelligence is high so they can take further advantage of it. The results can help pinpoint their strengths and show how they could be benefiting their lives.

Participants used 9-point scales $(1=$ not at all; $9=$ extremely) to answer two questions (collapsed below for brevity) concerning their preferences for feedback provision for others: "How worthwhile do you think it is to provide high school students with social intelligence feedback concerning their strengths [weaknesses]?" and two questions (collapsed below for brevity) concerning their inferences of others' feedback preferences: "How interested do you think high school students would be in finding out about their strengths [weaknesses]?" The order in which these four questions were presented was randomized across participants.

\section{Results}

In this experiment, as well as in the others reported in this paper, controlling for the number of words participants generated in the mindset tasks did not alter the statistical significance of any reported results. Participants' anticipations of others' feedback preferences were analyzed in a 2 (mindset: how versus why) $\times 2$ (feedback type: strengths versus weaknesses) ANOVA, with repeated measures on the last factor. Overall, participants more strongly inferred that high school students would desire feedback concerning their strengths $(M=7.82)$ than their weaknesses $(M=5.58), F(1,109)=124.60$, $p<.01$. Most relevant to our hypotheses, as shown in Fig. 2, participants' mindsets significantly moderated the degree to which they anticipated that others would prefer strengths- versus weaknesses-based feedback, $F(1,109)=4.04, p<.05$. Participants assigned to the abstract mindset condition $(M=6.02)$ anticipated that others would desire liabilities-based feedback to a stronger degree than did participants assigned to the concrete mindset condition $(M=5.06), t(109)=2.59$, $p<.02, d=.49$. The two groups did not differ significantly with respect to the degree to which they assumed that others would desire strengths-based feedback, $t<1$.

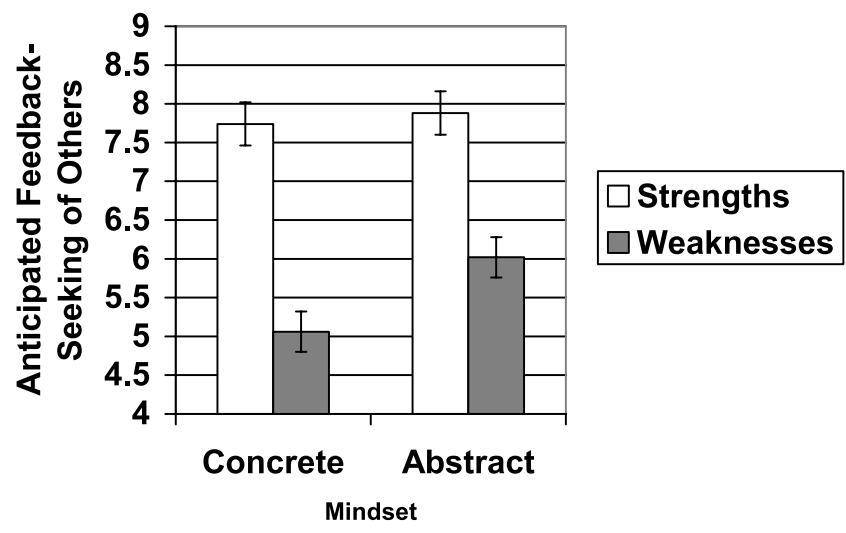

Fig. 2. Anticipated feedback seeking of others, as a function of type of feedback (strengths-based versus liabilities-based) and participants' mindsets (abstract versus concrete), Experiment 1.

Regarding participants' preferences for providing others with different types of feedback, overall, participants more strongly endorsed providing high school students with feedback concerning their strengths $(M=7.50)$ than their weaknesses $(M=6.68), F(1,109)=18.59, p<.01$. Most relevant to our hypotheses, as shown in Fig. 3, participants' mindsets significantly moderated the degree to which they preferred providing strengths- versus weaknesses-based feedback, $F(1,109)=5.82, p<.02$. Participants assigned to the concrete mindset condition $(M=7.81)$ more strongly endorsed providing strengthsbased feedback than did participants assigned to the abstract mindset condition $(M=7.17), t(109)=2.39$, $p<.02, d=.46$. The two groups did not differ significantly with respect to the degree to which they endorsed providing weaknesses-based feedback, $t<1$.

\section{Discussion}

Whereas negative feedback can be unpleasant to receive but provide longer-term benefits by guiding efforts

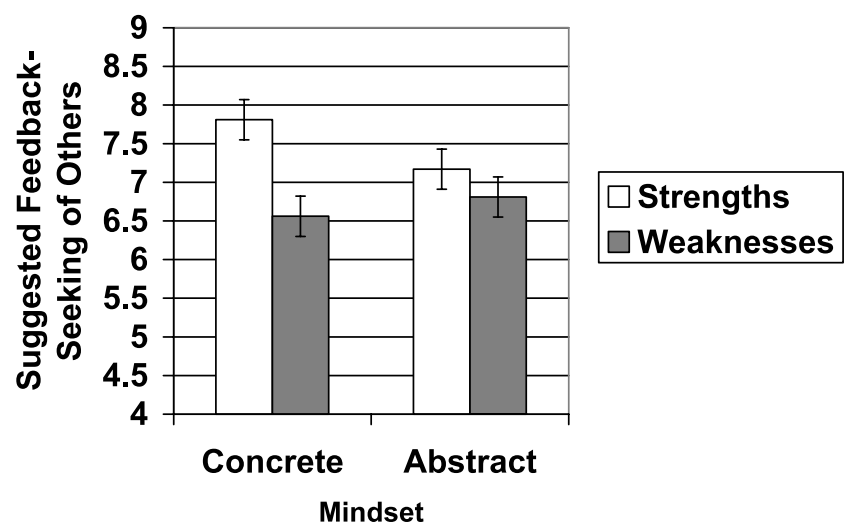

Fig. 3. Suggested feedback seeking of others, as a function of type of feedback (strengths-based versus liabilities-based) and participants' mindsets (abstract versus concrete), Experiment 1. 
toward self-improvement, positive feedback is pleasant to receive but, because it cannot guide any action toward improvement, offers less in the way of long-term benefits. We examined whether one's general mindset could influence the salience of these abstract versus concrete situational inducements, as they apply to one's anticipations and preferences of others' self-regulatory efforts. Would a generally abstract (rather than concrete) mindset, by making salient the abstract value of negative feedback rather than its immediate unpleasantness, influence the self-evaluative goals one anticipated and suggested that others adopt? Supporting this prediction, participants induced to adopt an abstract mindset, relative to those induced to adopt a concrete mindset, through completing a thought exercise concerning improving their physical health, were more likely to both expect and suggest that others receive feedback highlighting personal weaknesses needing improvement. These findings show that the accessibility of the cognitive operations of considering an activity's process or purpose can color how people construe newly encountered activities, including even those in which they themselves are not required to act. A practical implication is that considering how versus why to engage in some action could influence markedly the goals one anticipates, and endorses, that others to adopt in quite different domains. Merely considering how rather than why to take a weekend trip, for example, might convince a high school teacher that students desire sugarcoated rather than honest feedback.

\section{Experiment 2}

Features of situations can directly activate goal representations (e.g., Bargh, Gollwitzer, Lee-Chai, Barndollar, \& Trötschel, 2001; Fitzsimons \& Bargh, 2003). Accordingly, because any situation likely contains multiple goal-relevant features, we view the problem of understanding how people anticipate and guide others' self-regulatory efforts to depend critically on which features of others' situations people attend to. We suggest that an abstract mindset leads one to attend preferentially to the long-term, abstract rewards present in another's situation, thus activating goal representations maximizing those long-term, abstract opportunities. Although consistent with results of Experiment 1, this explanation has not yet received direct scrutiny. An alternative possibility, for example, is that people in abstract and concrete mindsets differ not in their attention to others' immediate versus long-term situational inducements but, rather, in their weighting of them, when deciding upon, or inferring, others' courses of action. Assuming either different salience of goal-relevant features of others' situations or different conclusions about the appropriate decisional weighting of equally salient situational features, these alternative possibilities implicate different underlying processes.

In Experiment 2, therefore, we more directly examined the influence of abstract and concrete mindsets on the salience of goal-relevant features of others' situations. Conceptualizing salient situational features as those that stand out prominently from others, thus capturing selective attention (e.g., Higgins, 1996), we measured salience in two ways. First, we assessed the speed with which participants could describe abstract and concrete goal-relevant features of others' situations. Salient information facilitates faster responses (e.g., Bachorowski \& Newman, 1990; Lamberts, 1998). Second, we assessed the extent to which participants expected abstract and concrete goal-relevant features of others' situations to impact others. Salient information facilitates stronger ascriptions of causal power (e.g., Sanbonmatsu, Shavitt, \& Gibson, 1994; Taylor \& Fiske, 1978). Following our reasoning, then, participants in abstract mindsets, relative to those in concrete mindsets, should: (a) be faster to list long-term, rather than immediate, goal-relevant features of others' situations and (b) expect long-term, rather than immediate, goal-relevant features of others' situations to have greater impacts on others.

Another aim of Experiment 2 was to examine an additional aspect of self-evaluation. Experiment 1 concerned inferences regarding others' pursuit of positive versus negative feedback. As suggested above, the latter type of feedback can guide long-term self-improvement, whereas the former type can provide a positive immediate experience. However, both positive and negative feedback can be either accurate or inaccurate. Rather than as a tradeoff between obtaining positive versus negative feedback, then, the self-regulatory challenge posed by self-evaluation can be characterized more rudimentarily as a tradeoff between obtaining highly accurate information or information accurate only to the extent that it does not damage one's self-esteem. We adopted this characterization in Experiment 2. Experiment $2 \mathrm{a}$ examined preliminarily whether the mindset effect obtained in Experiment 1 would generalize to this new context. Experiment $2 b$ additionally assessed the indicators of attentional salience discussed in the preceding paragraph. To probe further this work's generality, Experiment 2a concerned self-evaluation in the domain of social intelligence, as did Experiment 1, whereas Experiment $2 \mathrm{~b}$ concerned self-evaluation in the domain of career selection; moreover, in Experiment 2a, as in Experiment 1, the mindset induction concerned health improvement, whereas, in Experiment 2b, the mindset task induction concerned academic achievement. Finally, to gauge the potential linearity of the influence of abstract and concrete mindsets on inferring others' self-regulatory preferences, Experiment 2a included a no-mindset-induction control condition. 
Method

\section{Participants}

In exchange for credit toward various psychology courses, 97 undergraduates participated in Experiment 2a, and 103 undergraduates participated in Experiment $2 b$.

\section{Mindset inductions}

Participants were assigned randomly to complete either the abstract or the concrete versions of the mindset manipulation described in Experiment 1. The target of the thought exercise was either "health improvement," (Experiment 2a) or "academic improvement" (Experiment 2b). Experiment $2 \mathrm{a}$ additionally included a no-mindset-induction control condition, in which participants answered unrelated questionnaires lasting approximately $5-10 \mathrm{~min}$.

\section{Feedback descriptions}

Participants in Experiment 2a next read about the high school social-intelligence assessment described in Experiment 1, whereas participants in Experiment $2 \mathrm{~b}$ read about a high school assessment providing career feedback (adapted from Freitas et al., 2001; Experiment 4): "Our research group, together with several others, is developing a career assessment tool for high school students. We interview and observe professionals from a range of fields (arts, sciences, and businesses) and devise profiles of the personal qualities (abilities, likes, and dislikes) that lead to success and failure within particular careers. We then assess high school students on these same qualities and identify the careers likely to lead to each particular student's later failure and success. In deciding how to provide feedback to these students, we are seeking the advice of people of various age groups. Today we want your opinion about providing career feedback to high school students."

\section{Preferences regarding others' self-evaluative efforts}

The accuracy-versus-enhancement tradeoff was introduced to participants as follows: "Sometimes the most accurate feedback will also make the student feel quite upset, or disappointed with himself or herself. We can address this issue by providing feedback that is accurate only to the extent that it does not make them very upset or disappointed." To answer the question, "In your own opinion, how should we approach this issue?" participants used an 8-point scale (in Experiment 2a) or a 7-point scale (in Experiment 2b) to indicate their degree of preference with the anchors "greatly limit accuracy in order to preserve students' self-esteem" versus "maximize accuracy even if it greatly damages students' self-esteem."
Salience of abstract and concrete goal-relevant features of others' situations

Via computer, participants of Experiment $2 b$ were prompted four times to "Please list a feeling or emotion you think high school students might feel as they wait to receive career feedback." After providing each of the four emotions, participants were asked to answer the question: "To what extent do you think that students waiting to receive feedback will experience the emotion you just listed?" Participants also were prompted four times to "Please list one long-term goal high school students could reach by receiving career feedback." After providing each of the four goals, participants were asked to answer the question: "To what extent do you think that high school students receiving feedback will meet the goal you just listed?" The order in which participants listed goals and emotions was randomized across participants.

Response times to list abstract and concrete goal-relevant features. The computer recorded response times for each goal and emotion participants listed as well as the number of typed characters used for each response. Because both variables generated positively skewed distributions, both variables were subjected to natural logarithmic transformation (see Fazio, 1990; Judd \& McClelland, 1989). Emotion facilitation and long-term goal facilitation each were calculated separately as the average number of characters listed in each of four typed responses divided by the average response time to list each of four typed responses (for goal facilitation, $\alpha=.66$; for emotion facilitation, $\alpha=.67$ ). Creating a single index of participants' differential facilitation of these two constructs, each participant's emotion-facilitation score was subtracted from his or her goal-facilitation score. Thus, high scores on this index indicate faster responses (more characters typed per second) when listing others' long-term goals than when listing others' emotional experiences during assessment.

Expected impact of abstract and concrete goal-relevant features. Creating a single index of participants' differential impact ratings, each participant's average rating of the likelihood that feedback seekers would experience the four emotions $(\alpha=.63)$ was subtracted from his or her average rating of the likelihood that feedback seekers would realize the four goals $(\alpha=.63)$. Thus, high scores on this index indicate greater perceived likelihood that others' would realize the long-term goals participants listed than experience the emotions participants listed.

\section{Results}

Preferences regarding others' self-evaluative efforts Concerning the social intelligence feedback described in Experiment 2a, participants' assignment to the dif- 
ferent mindset conditions significantly affected the degree to which they preferred providing enhancing versus accurate feedback to others, $F(2,97)=4.48, p<.02$. As illustrated in Fig. 4, this finding reflected a relatively linear effect of assignment to the three different mindset conditions, as revealed by a planned linear contrast, $F(1,97)=8.95, p<.005$. Participants assigned to the abstract mindset condition $(M=5.24)$ endorsed providing accurate rather than enhancing feedback to a greater extent than did participants assigned to the concrete mindset condition $(M=4.12), t(64)=2.99$, $p<.01, d=.72$. Participants assigned to the no-mindset control condition scored in the middle $(M=4.74)$, although neither significantly above those in concrete mindset condition $(t(64)=1.53, n s, d=.40)$ nor significantly below those in the abstract mindset condition $(t(64)=1.45, n s, d=.34)$.

Concerning career feedback described in Experiment $2 \mathrm{~b}$, participants assigned to the abstract mindset condition also endorsed providing accurate rather than enhancing feedback to a greater extent $(M=4.15)$ than did participants assigned to the concrete mindset condition $(M=3.47), t(106)=2.14$, $p<.05, d=.41$.

Salience of abstract and concrete goal-relevant features of others' situations

Participants assigned to the abstract mindset condition demonstrated greater facilitation of others' longterm goals versus immediate emotions $(M=.067)$ than did participants assigned to the concrete mindset condition $\quad(M=.051), t(105)=2.20, p<.03, d=.43 .^{3}$ Moreover, participants assigned to the abstract mindset condition rated others' situations as more likely to impact long-term goals versus immediate emotional reactions $(M=.359)$ to a greater extent than did participants assigned to the concrete mindset condition $(M=.114), t(106)=1.93, p<.06, d=.37 .^{4}$ Suggesting that these two effects indeed reflect distinct aspects of the salience of goal-relevant features of others' situations, the effect of the mindset manipulation on par-

\footnotetext{
${ }^{3}$ An alternative but mathematically equivalent data-analytic approach to this question entails examining the goal and emotion facilitation measures separately in a 2 (Mindset: Abstract vs. Concrete) $\times 2$ (Facilitation Content: Goal versus Emotion) ANOVA, with repeated measures on the last factor. This analysis yields a twoway interaction identical in statistical significance to the $t$ test of the difference score reported above, $F(1,105)=4.88, p<.03$. We report the difference score in the text because it reflects our conceptual interest in relative focus on purpose- versus process-related phenomena, while providing a single composite variable that can be used in later correlation and regression analyses.

${ }^{4}$ Consistent with reasoning described in Footnote 3, a 2 (Mindset: Abstract vs. Concrete) $\times 2$ (Expected-Impact Content: Goal versus Emotion) ANOVA, with repeated measures on the last factor, yields a two-way interaction identical in statistical significance to the $t$ test of the difference score reported above, $F(1,106)=3.71, p<.06$.
}

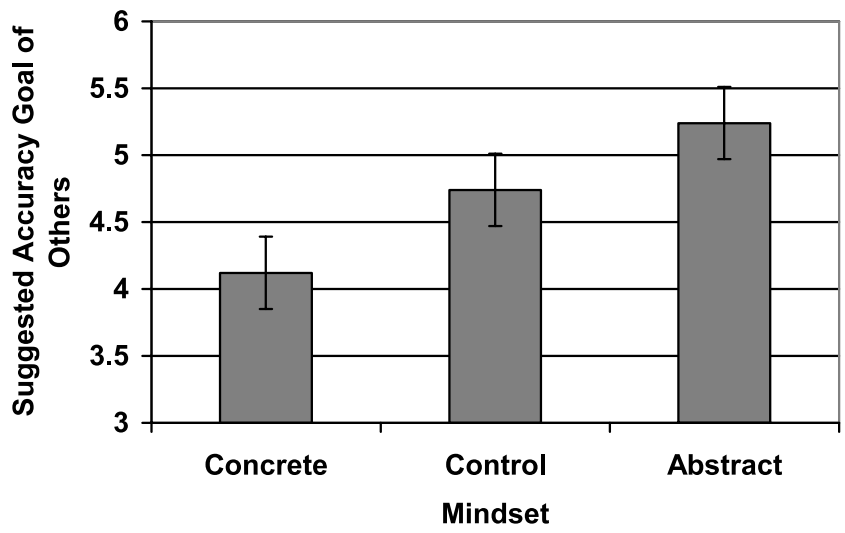

Fig. 4. Suggested accuracy (rather than self-enhancement) goals of others, as a function of assignment to concrete versus abstract mindset inductions or to a no-mindset control condition, Experiment 2a.

ticipants' facilitation scores was significant when controlling for their expected-impact scores, $\beta=.22$, $F(1,104)=4.95, p<.05$, and the effect of the mindset manipulation on participants' expected-impact scores was significant when controlling for their facilitation scores, $\beta=.21, F(1,104)=4.38, p<.05$.

Moreover, participants' preferences for others' receipt of accurate versus enhancing feedback correlated positively with both their facilitation scores $(r=.22$, $p<.05)$ and their expected-impact scores $(r=.25$, $p<.01)$. As shown in Fig. 5, and consistent with the possibility that these two aspects of the salience of goalrelevant features of others' situations help explain how the mindset manipulation influenced participants' preferences for others' receipt of the different types of feedback (see Kenny, Kashy, \& Bolger, 1998), in a simultaneous regression of participants' preferences for others' receipt of the different types of feedback on participants' mindset-induction assignment, facilitation scores, and expected-impact scores, the mindset induction was no longer a significant predictor $(\beta=$ $.11, F(1,104)=1.36, p>.25)$, whereas participants' facilitation and expected-impact scores each accounted for unique variance $(\beta=.20, F(1,104)=4.42, p<.05$; and $\beta=.23, F(1,104)=6.09, p<.05$, respectively).

\section{Content coding of emotions and goals}

To explore the contents' of participants' free responses, two independent raters unaware of participants' assignment to the different mindset conditions coded the contents of the long-term goals and immediate emotions participants listed. With an acceptable level of inter-rater agreement (average $\kappa=.82$ ), the raters classified the long-term goals into seven different categories (listed here in descending order from most commonly to least commonly listed: career development, academic development, self-knowledge, personal development, life happiness, financial gain, and interpersonal 


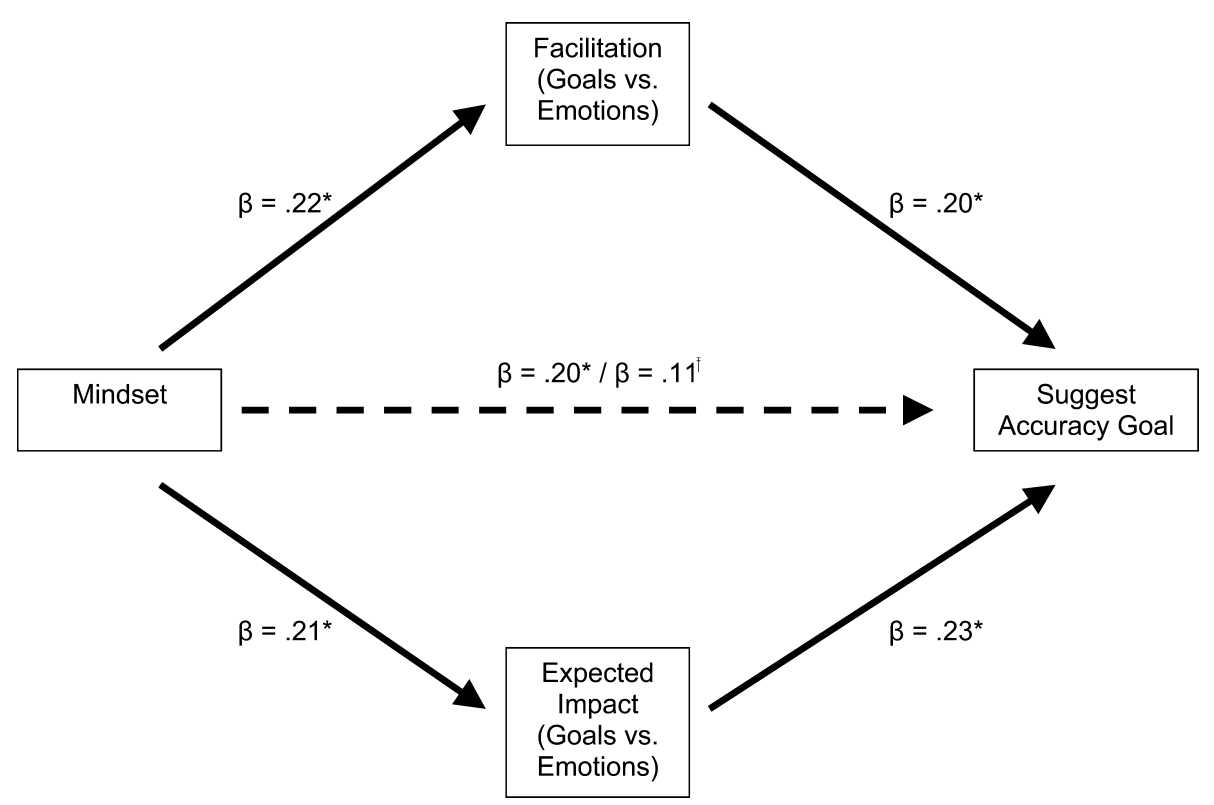

Fig. 5. Path analysis illustrating that participants' facilitation and perceived impact of others' long-term goals versus immediate emotional reactions helps explain their preferences for others’ self-evaluative goals, Experiment $2 \mathrm{~b}$. Note. ${ }^{*} p<.04 ;{ }^{\ddagger} p>.25$.

relationship development); $2.3 \%$ of participants' responses could not be placed into a goal category. Career development $(M=1.12)$ and academic development $(M=.94)$ were the most commonly listed goals, and interpersonal relationship development was the least commonly listed goal $(M=0.12)$. While applying a Bonferroni correction controlling for the multiple comparisons of abstract versus concrete mindset participants' listings of the seven types of goals, one significant effect emerged: participants assigned to the abstract condition listed a greater number of selfknowledge goals $(M=0.91)$ than did participants assigned to the concrete condition $(M=0.38), t(104)=$ $2.94, p<.05, d=.58$. Thus, approximately twice as many participants assigned to the abstract condition listed at least one self-knowledge goal (27 out of 53) as did participants assigned to the concrete condition (13 out of 53), $\chi^{2}(1, N=106)=7.87, p<.01$. Self-knowledge goals included goals such as "find out about themselves," "find out what they are good at," and "find out their strengths and weaknesses." Even when specifically directed to consider other's long-term goals, then, those with a high-level construal of the feedback situation were more likely than those with a low-level construal to view the situation as a vehicle by which others could attain self-knowledge.

With an acceptable level of inter-rater agreement (average $\kappa=.80$ ), the raters classified the emotions into four categories reflecting either positive or negative valence and either high or low arousal (see Feldman Barrett \& Russell, 1998); 1.8\% of participants' responses could not be placed into an emotion category. Participants' assignment to the different mindset conditions did not influence the particular types of emotions they listed (all $t \mathrm{~s}<1$ ). Overall, participants listed more negatively valenced emotions $(M=2.55)$ than positively valenced emotions $(M=1.34)$ and more high-arousal emotions $(M=3.29)$ than low-arousal emotions $(M=0.60)$. Accordingly, high-arousal/negative-valence emotions (e.g., anxious and nervous) were most commonly listed $(M=2.00)$, and low-arousal/positive-valence emotions (e.g., relieved and calm) were least commonly listed $(M=0.05)$.

\section{Discussion}

Findings from Experiment 2 show that mindsets influence in two ways the salience of outcomes others' situations appear to offer. First, participants in an abstract mindset, relative to those in a concrete mindset, were quicker to list the long-term goals than the immediate emotional reactions others' feedback situations could bring about. Such differential facilitation of longterm goals versus immediate emotional reactions should influence the goals people expect and endorse that others adopt (e.g., Higgins, 1996; Kruglanski, 1996). Confirming this expectation, greater facilitation of goals than of emotions was associated with preferring that others receive accurate rather than enhancing feedback. Second, participants in an abstract mindset, relative to those in a concrete mindset, expected that others' feedback situations were more likely to impact their longterm goals than their immediate emotional reactions. Because people's expectations of outcome likelihood influence their decisions to pursue particular courses of action (e.g., Bandura, 1989; Feather, 1989), such different expectancies should influence the goals people expect and endorse that others adopt. Confirming this 
prediction, higher expectancy that the feedback situation would impact others' long-term goals than immediate emotional reactions was associated with preferring that others receive accurate rather than enhancing feedback. Moreover, regression analyses suggested that these two variables - differential facilitation and differential expected impact of goal-relevant features of others' situations-helped explain the effect of the mindset manipulation on participants' degree of preferring others receive accurate versus enhancing feedback.

These findings also help address the possibility that our mindset manipulations influenced participants' preferred goals of others by influencing their level of engagement in others' situations. It is conceivable, for example, that, relative to concrete construals, abstract construals of others' situations could be either less engaging, due to a lack of focus on tangible details, or more engaging, by highlighting important, abstract aims. ${ }^{5}$ Differences in engagement, in turn, might influence one's level of concern or commitment that others receive the most useful feedback, thus perhaps influencing one's preferences for the type of feedback others receive. Suggesting that the current results do not depend on such differences in engagement, however, findings from Experiment $2 \mathrm{~b}$ demonstrated that some features of others' situations (e.g., others' immediate comfort) were most salient to participants in a concrete mindset, whereas others features (e.g., others' long-term aims) were most salient to participants in a concrete mindset. Rather than suggesting a main effect whereby people in abstract or concrete mindsets show greater overall engagement in others' situations, then, the data seem to show that people in a concrete mindset appear especially engaged by process-related features of others' situations, whereas people in an abstract mindset appear especially engaged by purpose-related features of others' situations.

\section{General discussion}

Understanding and influencing others' goals and intentions are central to navigating everyday life, evident even among very young children and infants (e.g., Kuhlmeier, Wynn, \& Bloom, 2003; Meltzoff, 1995; Montgomery, Moran, \& Bach, 1996). Seeking to understand mechanisms underlying these processes, we examined the role that abstract and concrete mindsets play in directing attention to particular goal-relevant aspects of others' situations. We assume that people will both anticipate and suggest that others pursue courses of action maximizing benefits and minimizing costs associated with

\footnotetext{
${ }^{5}$ We thank an anonymous reviewer for these interesting suggestions.
}

those goal-relevant features of others' situations that are most salient. Accordingly, we expected that participants in a generally abstract mindset, for whom the cognitive operation of considering activities' abstract aims is highly accessible, would be most likely to consider how others' self-evaluative situations could impact others' long-term aims of self-knowledge and self-improvement, thus leading these participants to both expect and suggest that others pursue accurate, even self-critical, feedback. In contrast, we expected that participants in a generally concrete mindset, for whom the cognitive operation of considering the concrete procedures comprising activities is highly accessible, would be most likely to consider how others' self-evaluative situations could impact others' immediate comfort during the feedbackacquisition process, thus leading these participants to both anticipate and suggest that others pursue pleasantto-receive, positive feedback.

Data from two experiments supported these hypotheses, whether participants' mindsets grew from thinking differentially abstractly about identical content matter concerning health improvement (Experiments 1 and 2a) or academic improvement (Experiment 2b); whether others' feedback was framed as strengths-based versus liabilities-based (Experiment 1) or as accurate versus self-enhancing (Experiments 2a and b); and whether others' self-evaluative domains concerned social intelligence (Experiments 1 and 2a) or career aptitude (Experiment 2b). Participants in abstract mindsets both anticipated (Experiment 1) and suggested (Experiments $2 \mathrm{a}$ and $\mathrm{b}$ ) that others pursue realistic rather than overly positive self-relevant information, and this effect appears to have been explained by the salience of abstract versus concrete goal-relevant features of others' situations (Experiment 2b).

\section{Implications for mindset research}

These findings illustrate a distinction between what we have termed abstract and concrete mindsets and what has served as an inspiration for this project, work on deliberative and implemental mindsets (e.g., Armor \& Taylor, 2003; Brandstaetter \& Frank, 2002; Gollwitzer, 1990; Gollwitzer \& Bayer, 1999, 1990; Gollwitzer, Heckhausen, \& Steller, 1990; Harmon-Jones \& Harmon-Jones, 2002). As reviewed earlier in this article, deliberative mindsets grow from weighing the pros and cons of not-yet-decided-upon courses of action, whereas implemental mindsets grow from planning the implementation of decided-upon courses of action. Our conceptual debt to this work, then, is clear, in that we also assume that focusing on the purpose (i.e., pros versus cons) or process (i.e., implementation) of an activity are cognitive operations that can become accessible and carry over from one task to another. However, our lack of any decisional differences between mindset manipu- 
lations gives rise to abstract/concrete mindset predictions that differ substantially from implemental/deliberative mindset predictions. Because implemental mindsets are assumed to generate broad determination to follow through on decided-upon courses of action, such mindsets have been theorized to promote positively biased views of situational affordances as overly supportive of one's current aims (Gollwitzer \& Kinney, 1989; Taylor \& Gollwitzer, 1995). In Experiment 2b, however, participants in concrete mindsets, generated through planning how to carry out an activity designated by the experimenter, viewed affordances of others' situations less favorably (i.e., as more likely to cause negative affective experiences than to cause the attainment of long-term aims) than did participants in abstract mindsets, generated through considering the abstract value of the same experimenter-designated activity. When not also influencing one's decisional status, therefore, a concrete, process-centered (versus abstract, purpose-centered) mindset does not appear to generate the level of commitment and determination required to foster positively biased assessments of situational affordances as overly supportive of one's aims. Instead, it appears that a concrete mindset serves to increase the salience of features of an activity that impact either positively or negatively the carrying out of the activity's underlying procedures.

More generally, we hope that this work contributes to efforts to understand the basic nature of mindsets. We view mindsets as a heightened accessibility of cognitive operations (Gollwitzer, 1990), whereby recently used cognitive operations are assumed to have temporarily higher activation levels, thus increasing their likelihood of being used to interpret new information (cf. Higgins, 1996). Our aim of dissociating abstract and concrete mindsets from participants' decisional statuses reflects an attempt to examine only such increased-accessibility influences. Continuing in this vein, for the sake of parsimony and clarity, we advocate maintaining conceptual distinctions between mindsets and related constructs (cf. Gibson, 1941). It might be tempting, for example, to view goals as essentially synonymous with mindsets (Stapel \& Koomen, 2001), especially if mindset manipulations generate effects apparently similar to those generated by implicit goal manipulations (Stapel \& Koomen, 2001). Common outcomes, however, do not necessarily signify a common cause. Whereas the accessibility of mindsets, like other momentarily activated cognitive material, can be expected to dissipate gradually across time (e.g., Higgins, 1996), goals, through marshalling motivation, are expected to remain accessible only until they are satisfied (e.g., Bargh et al., 2001; Zeigarnik, 1938). Implicitly primed affiliation goals, for example, continued to impact the behavior of only those participants who had not yet had an opportunity to attempt affiliative actions (Lakin \& Chartrand, 2003). In contrast, the mindset concept excludes by definition such "satiation" effects; otherwise, it would be impossible for the accessibility of a cognitive operation to carry over from a completed task to a new task. Future work, then, will benefit from maintaining distinctions between the mindset and goal concepts. In this spirit, such work might explore in more detail the time course of mindset accessibility effects, as well as how the cognitive procedures that give rise to mindsets are represented mentally in a manner that is apparently sufficiently coherent as to allow unified activation.

\section{Interpersonal implications}

These considerations suggest further interpersonal implications. Research on the self-fulfilling prophecy, for example, shows that people's interpersonal expectations influence how they treat others, which can lead others to behave in expectancy-confirming ways (e.g., Downey, Freitas, Michaelis, \& Khouri, 1998; Merton, 1948). Accordingly, by affecting which goals one infers that others will pursue in a situation, one's mindset might lead one to treat others such that they actually come to adopt goals that existed initially only in one's mindset-driven inferences. A related possibility is that one's mindset might affect how positively one judges others' behaviors. If an abstract mindset leads one to focus on the long-term benefits of negative feedback, for example, will a person in an abstract mindset judge a person seeking overly positive feedback to be an undisciplined hedonist? In contrast, if a concrete mindset leads one to focus on the comfort and ease of the self-evaluative processes, will a person in a concrete mindset judge a person seeking accurate, negative feedback to be a foolhardy glutton for punishment? Finally, the influence of abstract and concrete mindsets on people's anticipations of others' aims within a particular situation might differ markedly from their inferences of others' dispositional inferences. By making salient the abstract goal-relevant features of others' situations, for example, an abstract mindset appears to lead one to expect others to pursue the salient abstract, long-term aim. Upon actually observing another person striving toward an abstract aim, however, the salience of those situational features relevant to the long-term aim would support the inference that the person's behavior is driven by situational inducements rather than by an underlying disposition (e.g., Trope, 1986; Trope \& Gaunt, 1999). Accordingly, when it is clear that another's behavior reflects attempts at achieving a longterm aim, an observer in a concrete mindset, for whom the situational inducements relevant to the long-term aim are presumably less salient, should be more likely to infer an underlying disposition on the part of the actor. We look forward to future pursuit of these possibilities. 


\section{References}

Ach, N. (1910). Über die Willenstätitgkeit und das Denken [Acts of will and reasoning]. Leipzig: Quelle \& Meyer.

Adler, A. (1927). Understanding human nature. Garden City, NY: Garden City Publishers.

Andersen, S. M., \& Chen, S. (2002). The relational self: An interpersonal social-cognitive theory. Psychological Review, 109, 619-645.

Armor, D. A., \& Taylor, S. E. (2003). The effects of mindset on behavior: Self-regulation in deliberative and implemental frames of mind. Personality and Social Psychology Bulletin, 29, 86-95.

Bachorowski, J., \& Newman, J. P. (1990). Impulsive motor behavior: Effects of personality and goal salience. Journal of Personality and Social Psychology, 58, 512-518.

Bandura, A. (1989). Human agency in social-cognitive theory. American Psychologist, 44, 1175-1184.

Bargh, J. A., Gollwitzer, P. M., Lee-Chai, A., Barndollar, K., \& Trötschel, R. (2001). The automated will: Nonconscious activation and pursuit of behavioral goals. Journal of Personality and Social Psychology, 81, 1014-1027.

Bassili, J. N. (1989). Traits as action categories versus traits as person attributes in social cognition. In J. N. Bassili (Ed.), On-line cognition in person perception (pp. 61-89). Hillsdale, NJ: Lawrence Erlbaum.

Brandstaetter, V., \& Frank, E. (2002). Effects of deliberative and implemental mindsets on persistence in goal-directed behavior. Personality and Social Psychology Bulletin, 28, 1366-1378.

Brehm, J. W., \& Cohen, A. R. (1962). Explorations in cognitive dissonance. New York: Wiley.

Brown, R. W. (1958). How shall a thing be called? Psychological Review, 65, 14-21.

Cantor, N. (1994). Life task problem-solving: situational affordances and personal needs. Personality and Social Psychology Bulletin, 20, 235-243.

Cantor, N., Mischel, W., \& Schwartz, J. C. (1982). A prototype analysis of psychological situations. Cognitive Psychology, 14, 4577.

Carver, C. S., \& Scheier, M. F. (1999). Themes and issues in the selfregulation of behavior. In R. S. Wyer (Ed.), Perspectives on behavioral self-regulation: Advances in social cognition (Vol. 12, pp. 1-105). Mahwah, NJ: Lawrence Erlbaum Associates.

Chun, W. Y., Spiegel, S., \& Kruglanski, A. W. (2002). Assimilative behavior identification can also be resource dependent: The unimodel perspective on personal-attribution phases. Journal of Personality and Social Psychology, 83, 542-555, Discourse Processes, 21, 85-104.

Downey, G., Freitas, A. L., Michaelis, B., \& Khouri, J. (1998). The self-fulfilling prophecy in close relationships: Rejection sensitivity and rejection by romantic partners. Journal of Personality and Social Psychology, 75, 545-560.

Dweck, C. S. (1998). The development of early self-conceptions: Their relevance for motivational processes. In J. Heckhausen \& C. S. Dweck (Eds.), Motivation and self-regulation across the life span (pp. 257-280). NewYork: Cambridge University Press.

Dweck, C. S., \& Leggett, E. L. (1988). A social-cognitive approach to motivation and personality. Psychological Review, 95, 256273.

Emmons, R. A. (1989). The personal striving approach to personality. In L. A. Pervin (Ed.), Goal concepts in personality and social psychology (pp. 87-126). Hillsdale, NJ: Lawrence Erlbaum.

Fazio, R. H. (1990). A practical guide to the use of response latency in social psychological research. In C. Hendrick \& M. S. Clark (Eds.), Research methods in personality and social psychology: Review of personality and social psychology (Vol. 11, pp. 74-97). Newbury Park, CA: Sage.
Feather, N. T. (1989). Bridging the gap between values and actions: Recent applications of the expectancy-value model. In E. T. Higgins \& R. M. Sorrentino (Eds.), Handbook of motivation and cognition: Foundations of social behavior (Vol. 2, pp. 151-192). New York: Guildford.

Feldman Barrett, L., \& Russell, J. A. (1998). Independence and bipolarity in the structure of current affect. Journal of Personality and Social Psychology, 74, 967-984.

Fitzsimons, G. M., \& Bargh, J. A. (2003). Thinking of you: Nonconscious pursuit of interpersonal goals associated with relationship partners. Journal of Personality and Social Psychology, 84, 148-164.

Freitas, A. L., Salovey, P., \& Liberman, N. (2001). Abstract and concrete self-evaluative goals. Journal of Personality and Social Psychology, 80, 410-424.

Gibson, J. J. (1941). A critical review of the concept of set in contemporary experimental psychology. Psychological Bulletin, 38 , $781-817$.

Gibson, J. J. (1986). The ecological approach to visual perception. Mahwah, NJ: Lawrence Erlbaum, Original work published 1979.

Gilbert, D. T. (1998). Ordinary personology. In D. T. Gilbert, S. T. Fiske, \& G. Lindzey (Eds.), Handbook of social psychology (Vol. 2, 4th ed., pp. 89-150). New York: McGraw Hill.

Gollwitzer, P. M. (1990). Action phases and mind-sets. In E. T. Higgins \& R. M. Sorrentino (Eds.), Handbook of motivation and cognition: Foundations of social behavior (Vol. 2, pp. 53-92). New York: Guilford.

Gollwitzer, P. M., \& Bayer, U. (1999). Deliberative versus implemental mindsets in the control of behavior. In S. Chaiken \& Y. Trope (Eds.), Dual-process theories in social psychology (pp. 403-422). New York: Guilford.

Gollwitzer, P. M., Heckhausen, H., \& Ratajczak, H. (1990). From weighing to willing: Approaching a change decision through pre- or postdecisional mentation. Organizational Behavior and Human Decision Processes, 45, 41-65.

Gollwitzer, P. M., Heckhausen, H., \& Steller, B. (1990). Deliberative vs. implemental mindsets: Cognitive tuning toward congruous thoughts and information. Journal of Personality and Social Psychology, 59, 1119-1127.

Gollwitzer, P. M., \& Kinney, R. F. (1989). Effects of deliberative and implemental mindsets on illusion of control. Journal of Personality and Social Psychology, 56, 531-542.

Grant, H., \& Dweck, C. S. (1999). A goal analysis of personality and personality coherence. In D. Cervone \& Y. Shoda (Eds.), The coherence of personality: Social-cognitive bases of consistency, variability, and organization (pp. 345-371). New York: Guilford.

Harmon-Jones, E., \& Harmon-Jones, C. (2002). Testing the actionbased model of cognitive dissonance: The effect of action orientation on postdecisional attitudes. Personality and Social Psychology Bulletin, 28, 711-723.

Heckhausen, H. (1986). Why some time out might benefit achievement motivation research. In J. H. L. van den Bercken, T. C. M. Bergen, \& E. E. J. De Bruyn (Eds.), Achievement and task motivation (pp. 739). Lisse, The Netherlands: Swets \& Zeitlinger.

Heckhausen, H., \& Gollwitzer, P. M. (1987). Thought contents and cognitive functioning in motivational versus volitional states of mind. Motivation \& Emotion, 11, 101-120.

Higgins, E. T. (1996). Knowledge activation: Accessibility, applicability, and salience. In E. T. Higgins \& A. W. Kruglanski (Eds.), Social psychology: Handbook of basic principles (pp. 133-168). New York: Guilford Press.

Judd, C. M., \& McClelland, G. H. (1989). Data analysis: A modelcomparison approach. Orlando, FL: Harcourt Brace Jovanovich.

Kenny, D. A., Kashy, D. A., \& Bolger, N. (1998). Data analysis in social psychology. In D. T. Gilbert, S. T. Fiske, \& G. Lindzey 
(Eds.), Handbook of social psychology (Vol.1, 4th ed., pp. 233-265). New York: McGraw-Hill.

Kruglanski, A. W. (1996). Goals as knowledge structures. In P. M. Gollwitzer \& J. A. Bargh (Eds.), The psychology of action: Linking cognition and motivation to behavior (pp. 599-618). New York: Guilford

Kuhlmeier, V., Wynn, K., \& Bloom, P. (2003). Attribution of dispositional states by 12-month-olds. Psychological Science, 14, 402-408.

Külpe, O. (1904). Versuche über Abstraktion [Experiments on abstraction]. Berichtüber den 1. Kongre $\beta$ für Experimentelle Psychologie, 1, 56-68.

Kunda, Z. (1990). The case for motivated reasoning. Psychological Bulletin, 108, 480-498.

Lakin, J. L., \& Chartrand, T. L. (2003). Using nonconscious behavioral mimicry to create affiliation and rapport. Psychological Science, 14, 334-339.

Lamberts, K. (1998). The time course of categorization. Journal of Experimental Psychology: Learning, Memory, and Cognition, 24, 695-711.

Liberman, N., \& Trope, Y. (1998). The role of feasibility and desirability considerations in near and distant future decisions: A test of temporal construal theory. Journal of Personality and Social Psychology, 75, 5-18.

Meltzoff, A. M. (1995). Understanding the intentions of others: Reenactments of intended acts by 18 -month-old children. Developmental Psychology, 31, 838-850.

Merton, R. K. (1948). The self-fulfilling prophecy. Antioch Review, 8, 193-210.

Mischel, W. (1973). Toward a cognitive social learning reconceptualization of personality. Psychological Review, 80, 252-283.

Mischel, W., Ebbesen, E. B., \& Zeiss, A. R. (1973). Selective attention to the self: Situational and dispositional determinants. Journal of Personality and Social Psychology, 27, 129-142.

Mischel, W., Shoda, Y., \& Rodriguez, M. L. (1989). Delay of gratification in children. Science, 244, 933-938.

Montgomery, D. E., Moran, C., \& Bach, L. M. (1996). The influence of nonverbal cues associated with looking behavior on young children's mentalistic attributions. Journal of Nonverbal Behavior, 20, 229-249.

Moretti, M. M., \& Higgins, E. T. (1999b). Own versus other standpoints in self-regulation: Developmental antecedents and functional consequences. Review of General Psychology, 3, 188223.

Proffitt, D. R., Stefanucci, J., Banton, T., \& Epstein, W. (2003). The role of effort in perceiving distance. Psychological Science, 14, 106112.

Read, S. J., \& Miller, M. (1993). Rapist or "regular guy": Explanatory coherence in the construction of mental models of others. Personality and Social Psychology Bulletin, 19, 526-540.

Rachlin, H. (2000). The science of self-control. Cambridge, MA: Harvard University Press.

Rees, H. J., \& Israel, H. E. (1935). An investigation of the establishment and operation of mental sets. Psychological Monographs, 46, 1-26.

Rochat, P. (1995). Perceived reachability for self and others for 3- to 5year old children. Journal of Experimental Child Psychology, 59, 317-333.

Sanbonmatsu, D. M., Shavitt, S., \& Gibson, B. D. (1994). Salience, set size, and illusory correlation: Making moderate assumptions about extreme targets. Journal of Personality and Social Psychology, 66, $1020-1033$

Semin, G. R., \& Fiedler, K. (1988). The cognitive functions of linguistic categories in describing persons: Social cognition and language. Journal of Personality and Social Psychology, 54, 558568.

Semin, G. R., \& Fiedler, K. (1992). The configuration of social interaction in interpersonal terms. In G. R. Semin \& K. Fiedler (Eds.), Language, interaction and social cognition (pp. 58-78). London: Sage.

Semin, G. R., \& Smith, E. R. (1999). Revisiting the past and back to the future: Memory systems and the Linguistic representation of social events. Journal of Personality and Social Psychology, 76, 877892.

Shah, J. (2003). Automatic for the people: How representations of significant others implicitly affect goal pursuit. Journal of Personality and Social Psychology, 84, 661-681.

Stapel, D. A., \& Koomen, W. (2001). The impact of interpretation versus comparison mindsets on knowledge accessibility effects. Journal of Experimental Social Psychology, 37, 134-149.

Stroffregen, T. A., Gorday, K. M., Sheng, Y., \& Flynn, S. B. (1999). Perceiving affordances for another person's actions. Journal of Experimental Psychology: Human Perception and Performance, 25, $120-136$

Taylor, S. E., \& Fiske, S. T. (1978). Salience, attention, and attribution: Top of the head phenomena. In L. Berkowitz (Ed.), Advances in experimental and social psychology (11, pp. 249-288). San Diego, CA: Academic Press.

Taylor, S. E., \& Gollwitzer, P. M. (1995). Effect of mindset on positive illusions. Journal of Personality and Social Psychology, 69, 213-226.

Trope, Y. (1986). Identification and inferential processes in dispositional attribution. Psychological Review, 93, 239-257.

Trope, Y., \& Alfieri, T. (1997). Effortfulness and flexibility of dispositional judgment processes. Journal of Personality and Social Psychology, 73, 662-674.

Trope, Y., \& Gaunt, R. (1999). A dual-process model of overconfident attributional inferences. In S. Chaiken \& Y. Trope (Eds.), Dualprocess theories in social psychology. New York: Guilford.

Trope, Y., \& Fishbach, A. (2000). Counteractive self-control in overcoming temptation. Journal of Personality and Social Psychology, 78, 493-506.

Trope, Y., \& Liberman, N. (2003). Temporal construal. Psychological Review, 110, 403-421.

Trope, Y., \& Neter, E. (1994). Reconciling competing motives in selfevaluation: The role of self-control in feedback seeking. Journal of Personality and Social Psychology, 66, 646-657.

Vallacher, R. R., \& Kaufman, J. (1996). Dynamics of action identification: Volatility and structure in the mental representation of behavior. In P. M. Gollwitzer \& J. A. Bargh (Eds.), The psychology of action (pp. 260-282). New York: Guilford.

Vallacher, R. R., \& Wegner, D. M. (1985). A theory of action identification. Hillsdale, NJ: Lawrence Erlbaum Associates.

Vallacher, R. R., \& Wegner, D. M. (1987). What do people think they're doing? Action identification and human behavior. Psychological Review, 94, 3-15.

Vallacher, R. R., \& Wegner, D. M. (1989). Levels of personal agency: Individual variation in action identification. Journal of Personality and Social Psychology, 57, 660-671.

Vallacher, R. R., Wegner, D. M., McMahan, S. C., Cotter, J., \& Larsen, K. A. (1992). On winning friends and influencing people: Action identification and self-presentation success. Social Cognition, 10, 335-355.

Zakay, D., \& Tsal, Y. (1993). The impact of using forced decisionmaking strategies on post-decisional confidence. Journal of Behavioral Decision Making, 6, 53-68.

Zeigarnik, B. (1938). On finished and unfinished tasks. In W. D. Ellis (Ed.), A source book of Gestalt psychology. New York: Humanities Press. 